\title{
Using Mobile Technology for Problem Need Identification in School-aged Children Environment
}

\author{
Gisli THORSTEINSSON ${ }^{1}$, Andrei NICULESCU ${ }^{2}$ \\ ${ }^{1}$ University of Iceland, v/Stakkahlid, 101, Reykjavik, Iceland \\ cdt@hi.is \\ ${ }^{2}$ Spiru Haret University, 13 Ion Ghica Street, Bucharest 3, Romania \\ andreiniculescu@hotmail.com
}

\begin{abstract}
This paper attempts to examine the value of using smartphones as a notebook (SN) in young students' homework to support their ideation skills. Participating case study students easily made use of the SN at home for recording problems and needs (PN) as well as initial solutions they had identified in their environment. The study has proven that the SN is an important tool that also supported communication and collaboration with parents. Furthermore, it was an important media in transporting homework to school and a great help in starting off lessons. Moreover, the SN increased the students' interest for their homework, as they found it practical and easy to use. When the SN was used as a problem-needs identification tool it activated the students' ideation at the initial state of their ideation. The SN also enabled younger students to generate the content of their coursework and thus improved the home-school connection.
\end{abstract}

Keywords: Problem-need identification (PNI), ideation, Smartphones, schoolwork.

\section{Introduction}

Fast progress in information and communication technologies has supported production of advanced mobile devices. Such devices are commonly used by students at different age. It is important during the design of modern educational context to include mobile devices that are capable of data transfers and accessible from everywhere. Using mobile devices can enable students to record information in their home environment with a view to using it as a source for their school work. The information can easily be accessed both at home and in lessons at school.

In this research smartphones were used by students instead of conventional notebooks to support their ideation. Notebooks have been used by many inventors, designers, engineers and scientists, such as Edison, da Vinci, Jefferson, Einstein and Tesla (Grisson \& Pressman, 2000). They used them to record their problem-needs identifications, initial ideas and results from observations.
Such a notebook offers users to keep track of all ideas that pop up during the day. If we don't record them, they will be forgotten. Some of them might look trivial to us, as others look very impressive and valuable. However, all of them might have the potential to become something more. One of the biggest opportunities such a notebook gives is to allow ideas to be forgotten for a while and be accessible later. A smartphone can also be used in a modern school context as a notebook to support communication and collaboration during students work. It can, furthermore, be a great help in starting off school work based on students ideation.

A notebook is not a legal document to enable protection of new ideas. However, it is valuable, in this context, as it offers a chronological record of a new idea (an invention or design) and its reduction to practice. Each entry must be signed and dated, by a witness. The witness should not be someone with a conflict of interest, but a member of an official institution. If an inventor
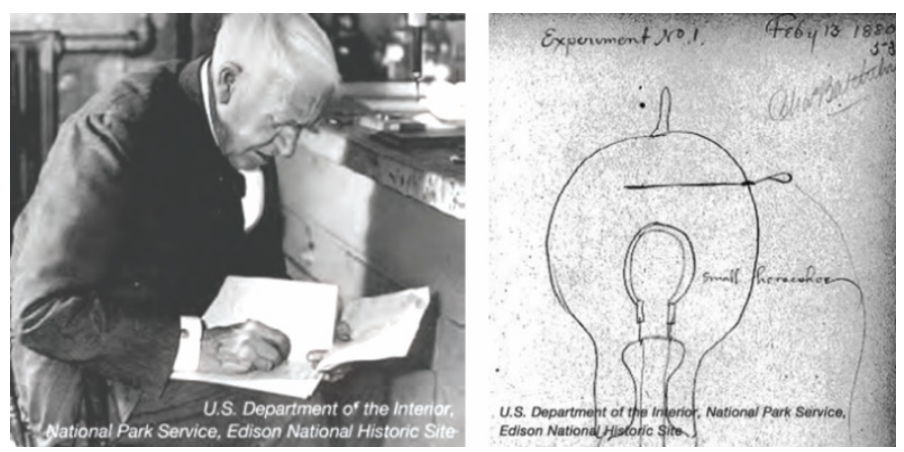

Figure 1. Thomas Edison using his notebook and his drawing of the first electric light bulb from his notebook. 
or a designer ever has to go to court to prove up on a new idea, then the witness would be called to the stand to testify that the signature is theirs and they signed that page on that date.

The design of the smartphone application used in this research (see image 2) was based on observations of young students recording ideas. They seemed to be at ease drawing small basic pictures of the ideas using a specific pen, in the way that they could have the whole picture within their range of vision at the same time, just as they see the idea in their mind's eye. the practice of innovative thinking, which needs intellectual vision and insight (Hiley et al., 2007; Jay \& Perkins, 1997).

Many techniques to enhance ideation reflect problem definition, rather than problem solving, and an innovative result may initially depend on defining a problem or need innovatively (Jay \& Perkins, 1997). PNI plays a vital role in this research, as the process begins in the students' own settings. Part of ideation relies on PNI and it reinforces individual's capabilities to solve PNs in daily life
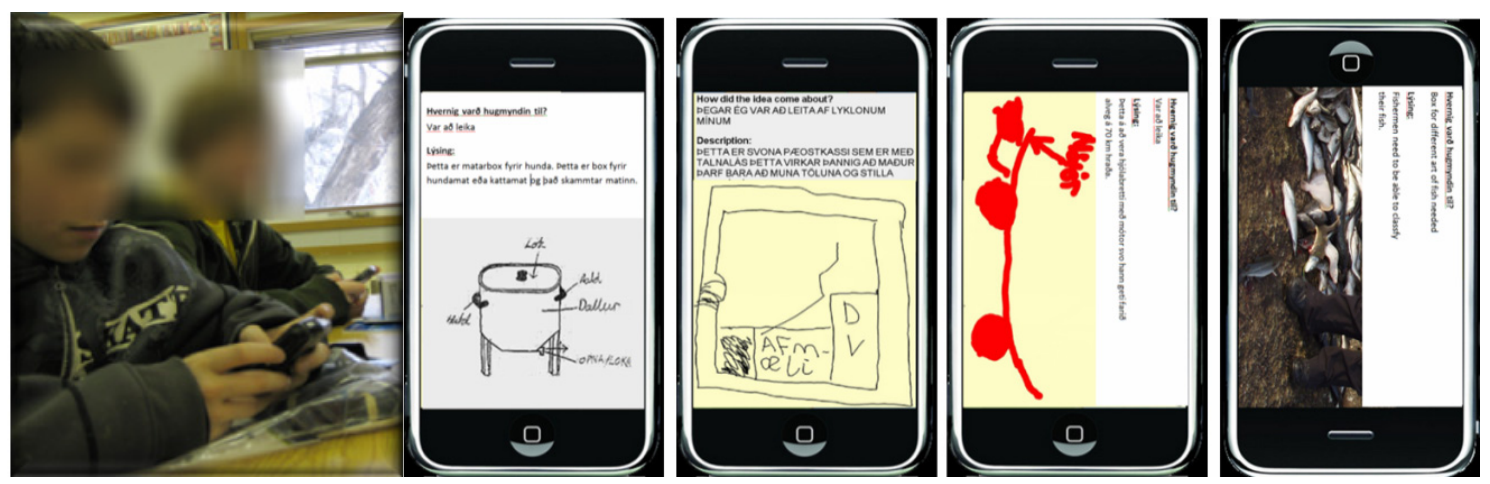

Figure 2. Shows students using their smartphones during a lesson with examples.

With the smartphone they were also able to take photographs or simply record a verbal description of the need or problem they had identified. They could access their ideas in lessons and share online.

The paper will first look into the literature of Problem-Need Identification (PNI) and ideation. Subsequently, the authors define the research methodology and report the results. Then, they discuss the results and make their conclusions.

\section{Problem-Need Identification (PNI)}

PNI is often included in techniques for innovative thinking (Hiley et al., 2007) and are also an important part of ideation. Guilford (1950), who first defined divergent and convergent thinking (Clapman 2003), recognised $\mathrm{PN}$, in the context of sensitivity to problems, which may imply an emotional tendency rather than a thinking skill. PNI can be broadly defined as a process that precedes PN solving (Runco \& Dow, 1999). The specific processes of this comprise PN discovery; construction; expression; posing; definition and identification. PNI is a process of discovery and is the original part of ideation: this involves
(Thorsteinsson, 2002). PNI is a vital part of the ideation: in its novel or conventional form, a PN may have been remarkably difficult. Nevertheless, the solution to a PN may be noticeable, once it has been appropriately defined and presented (Hiley et al., 2007).

\section{Ideation}

The Webster's Dictionary (2005), describes ideation as 'the faculty or capacity of the mind for forming ideas; the exercise of this capacity; the act of the mind by which objects of sense are apprehended and retained as objects of thought' (p725).

The ideation process in this research project began in the student's home environment, in seeking needs and problems as a foundation for idea generation inside the school. The SN was an important source of information for the student and enabled the teacher to see the student's ideas and directions. The teacher's role was to develop and maintain students' innovative attitude, assisting them to look for solutions and ways of bringing their ideas to understanding (e.g. as drawings or descriptions) (Thorsteinsson, 1998). This part of the ideation 
personalises the process and links the activity to earlier knowledge and understanding.

Ideation requires individuals to look for numerous new approaches to problems. This is named a divergent style (Vidal, 2006), counting both exceptional and usual responses, which may need random relationships of dissimilar areas, sets of knowledge or ideas. Most areas favour group brainstorming as a support to ideation. Nevertheless, latest research studies have advised that individual brainstorming produces more effective outcomes than group meetings (Paulus et al., 2002; Larey \& Paulus, 1999; Dugosh et al., 2000).

Vidal's (2006) research also showed that, in both individual and group ideation, it is more actual to begin with divergent thinking, in order to generate as many ideas or solutions as possible and, afterwards, to change to convergent thinking, in order to select the most promising ideas (see figure 3 ). solutions. After this the students worked with individual solutions, by using a cad program and made descriptions.

The research questions of the study were the following:

1. Can a SN be used for PNI?

2. How will this affect the students' ideation?

3. What are the origins of the students' ideation?

4. What is the value of problem-need identification in the school context?

The study was carried out in three phases. The first phase included the review of the students' work and the second phase included interviews with the teacher and the students in order to shed further light on some areas of practice. These semi-structured interviews were designed to explore issues regarding the

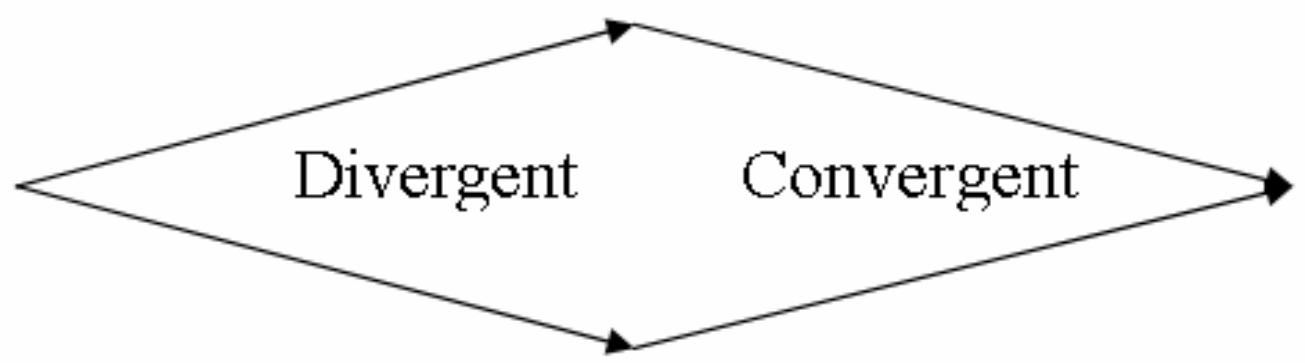

Figure 3. The relationship between divergent and convergent thinking

Other researchers have observed innovation on an individual basis. Encouraging ideation at an individual level may result in enhanced innovativeness at group level (Smith, 2003).

\section{The Research Design and the Methodology}

The research was based on three case studies, including three lessons, each. Eight, 12 year old, chosen students volunteered in each study. They were informed about the use of the smartphone and how they could use it to document needs and problems they would find in their environment. Then they worked with the smartphone at home and subsequently brought it with them to the lessons to discuss their findings as a group to enable their idea generation. They learned to share their findings, brainstorm together and find common students' usages of the SN and how it affected their course work. The interviews were conducted by one of the authors.

The research was undertaken through a phenomenographic approach because of its suitability to the examination of a phenomenon such as PNI. Phenomenography seeks to describe, analyse and realize the methods in which people experience aspects of the world about them. The point of departure that sets apart this approach from many others, is the principle that phenomenography seeks to examine neither the phenomenon, nor the individuals who experience the phenomenon, but the relation between the two. The results of a phenomenographic study are represented as an account of all of the conceivable conceptions that a specific group can have about a phenomenon (Marton \& Booth, 1997), 
in this case children's capabilities of using the SN for PNI.

\section{The Main Research Outcomes}

The following findings were established by analysing the interviews:

- The students easily used smartphones as notebooks for PNI at home and in lessons

- Using the SN affected the students' interest to identify needs at home

- The SN was useful to get students started in the lesson to find ideas

- PNI enabled the students to generate the content of the course

- The students were able to identify needs, problems and ideas at home

- The students were supported by their families during their homework

- The students did their homework and got feedback from their parents

- Discussing ideation at home increased the students motivation

- Students often registered solutions instead of PN.

The data from the SN gave information about the background of the students work.
Gunnardottir (2001) recognized social relations between the home and the classroom as vital. She argued that ideation work in schools is associated to social constructivism (Edwards, 2001; Thorsteinsson, et al. 2010), and this refers to work of Dewey, Piaget and Vygotsky.

Students learned to use the smartphone through experience, but were also trained in this by the teacher. Using the SN supported their work and made it possible for the students to generate the content of their school work. Social constructivists examine how individuals use social activities to alter their circumstances of existence and their self-image (Shotter, 1993:111) and develop into active partakers in the society that surrounds them, both inside and outside school (Edwards, 2001). This shows the extent to which a high degree of learner autonomy and restricted direct teaching by the teacher can be indicative of Vygotsky's Zone of Proximal Development (Vygotsky, 1978).

Using the SN and discussing PNI at home enlarged the students' motivation and interest for their school work. It also allowed the students to establish the course content. Wenger (2005) argued that school is no longer the heart of education or the location where students come to gain knowledge to use in the outer world. Education takes place in life and the classroom is just one side of this. With

Table 1. Summarizes the data and shows whom the students' ideas were for

\begin{tabular}{|l|l|}
\hline Variants & Numbers and / or percentages \\
\hline Total numbers of students & 24 \\
\hline Total numbers of ideas & 58 \\
\hline Solutions for everybody & $37 / 64 \%$ \\
\hline Solutions for students & $9 / 16 \%$ \\
\hline Solutions for the teacher & $2 / 3 \%$ \\
\hline Solutions for the student's family & $10 / 17 \%$ \\
\hline Solutions for concerning general problems & $100 \%$ \\
\hline
\end{tabular}

\section{Discussion}

Throughout the research, students' homework was seen as vital, as it generated the foundation of their course work. Homework was based on the PNI, the use of the SN and communication with families. Furthermore, homework also facilitated social relations inside and between the students' homes and the classroom. regards to social constructivist theories, social constructivists see the environment in which learning takes place as central, together with the social contexts that learners bring to their learning setting (Gredler, 1997; Jackson, et al. 2006). They stress the significance of culture and context in understanding what take place in society and the construction of knowledge is based on this understanding (Jackson, et al. 2006; Derry, 1999; McMahon, 1997; Thorsteinsson, et al. 2010). According to Gredler (1997), knowledge, meaning and 


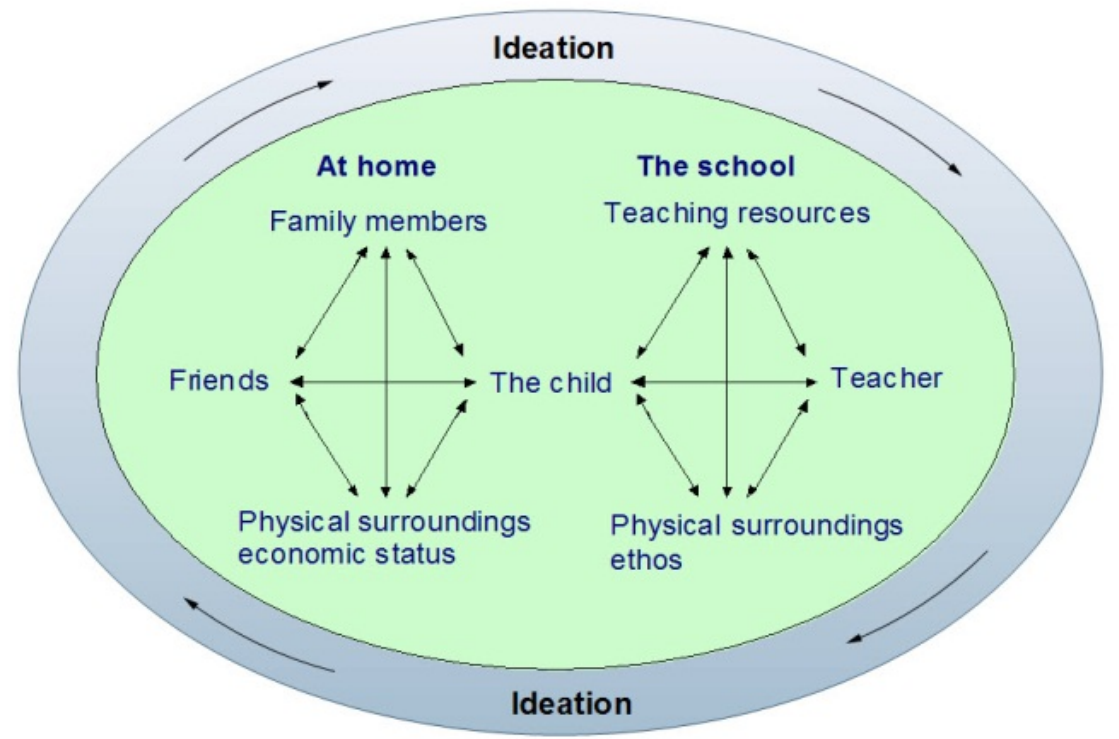

Figure 4. The model illustrates relations between a student's home life and ideation classes.

understanding of the world can be dealt with in the classroom from both the view of the individual learner and the collective view of the whole class (Cobb, 1995; Gredler, 1997).

The teacher thus placed an emphasis on the students' PNI during the course and supported their idea generation by brainstorming with them during lessons (using their homework). Students are part of the constructed environment and take part in constructing it. In turn, the environment is one of the characteristics that shape students (Bredo, 1994; Gredler, 1997). When a student's mind is engaged, they are interacting with the environment. Hence, if the environment and the social relations of students change, the tasks of each student may also change (Bredo, 1994; Gredler, 1997; Jackson, et al. 2006). As a result, education should not take place in separation from the student's home.

According to the teacher observations in this research, the SN seemed to increase students' interest in identifying ideas and thus most likely fostered their interest in ideation. This was the initial state of the ideation and thus triggered students' ideation: the SN helped the students to remember, record and define identified needs and problems. According to Runco \& Dow (1999), a vital step in solving problems is to first define them and the above authors also considered that, in training students to solve problems, such students also need to be able to work with unclear tasks, in order to look after clarification.
It was crucial that the teacher understood the significance of the homework and was able to make use of it for the purpose of idea generation (see similarities in Jonassen, 2002; Hutchison, 2006 and Gredler, 1997). Consequently, the teacher placed a weight on the students' PNI during their homework and supported their idea generation throughout lessons. However, the students often recorded solutions in the notebook instead of needs and problems (Thorsteinsson \& Denton, 2006, Thorsteinsson, et al. 2007). Runco and Dow (1999) studied that an innovative solution to a problem may depend on how the problem has been recognized and found; problem solving may also depend on problem definition. In its original form, the problem may have been remarkably difficult, but a redefinition can make that same problem easier to work out. The specific processes under PNI include problem identification, problem construction, problem expression and problem posing and definition (Runco, 2007).

The study showed that the parents gave comments to their children when they talked about their ideation, using the SN, and that this augmented their motivation. Researchers have identified that parental participation increases a child's learning attainment (see further in Cooper, Jackson, Nye, \& Lindsay, 2001; McCarthey, 2000) and have also pointed out that parental interaction with students throughout the completion of homework is a vital factor in improving parental involvement, 
thus improving the home-school connection (see further in Cooper et al., 2001; HooverDempsey et al., 2001; McCarthey, 2000). Almost all of the parents gave their child some support, but none of them discussed needs or problems, only ideas. However, students often talked with someone in their family, in order to achieve more PN. Therefore, probably the majority of solutions generated by the students suited everybody (see table 1 ).

\section{Conclusion}

Using the SN was considered vital, as it generated the course tasks through the identification of PN (Runco \& Dow, 1999; Luckin et al., 2007). PN identified by the students at home constituted the initial state of the students' ideation and activated idea generation (Thorsteinsson \& Denton, 2006). This was supported by the use of the SN, students' communication with their families and social interaction within the students' homes and the classroom.

The SN was used as a problem-needs identification tool and the initial state of the students' ideation activated their idea generation. As seen in the students' interviews, using the SN seemed to increase the students' interest in finding solutions. Runco and Dow (1999) informed that an essential step in solving problems is to define them first and the $\mathrm{SN}$ helped the students to remember, record and define identified needs and problems. Runco and Dow (1999) also asserted that, in training students to solve problems, they must be able to handle ambiguous tasks, in order to learn to clarify them.

The SN enabled the context of the learners' generated content of a course and became a tool for communication, supporting social interactions between school and home. It played a vital role in connecting these two elements together and was necessary in communicating ideas.

\section{REFERENCES}

1. BREDO, E., Reconstructing Educational Psychology: Situated Cognition and Deweyian Pragmatism. Educational Psychologist, Vol. 29(1), pp. 23-25, 1994.

2. CLAPHAM, M. M., The Development of Innovative Ideas through Creativity
Training. In The International Handbook on Innovation, Edited by LV Shavinina. Elsevier Science, Oxford, 2003, pp. 366-376.

3. COBB, P., Continuing the Conversation: A Response to Smith. Educational Researcher, Vol. 24(6) , 1995, pp. 25-27.

4. COOPER, H., K. JACKSON, B. NYE, J. J. LINDSAY, A Model of Homework on the Performance Evaluations of Elementary School Students. The Journal of Experimental Education, Vol. 69(2), 2001, pp. 181-199.

5. DERRY, S. J., A Fish Called Peer Learning: Searching for Common Themes. In O'Donnell, A.M. \& King, A. (Eds.), Cognitive perspectives on peer learning. Lawrence Erlbaum. Mahwah, NJ, 1999, pp. 197-211.

6. DUGOSH, K. L., P. B. PAULUS, E. J. ROLAND, H.-C. YANG, Cognitive Stimulation in Brainstorming. Journal of Personality and Social Psychology, Vol. 79(5), 2000, pp. 722-735.

7. EDWARDS, A., Researching Pedagogy: a Sociocultural Agenda. Pedagogy, Culture and Society, Vol. 9(2), 2001, pp. 161-186.

8. GREDLER, M. E., Learning and Instruction: Theory into Practice (3rd ed). Prentice-Hall, Upper Saddle River, NJ, 1997.

9. GRISSON, F., D. PRESSMAN, The Inventor's Notebook. 3rd Edition, Nolo, 2000.

10. GUILFORD, J. P., Creativity. American Psychologist, Vol. 5(9), 1950, pp. 444-454.

11. GUNNARSDOTTIR, R., Research in Innovation Education: Socio-Cultural Methods for Research and Analysis for Defining Educational Phenomenon. Visions on Sloyd and Sloyd Education. Techno Series: Research in Sloyd Education and crafts science B, Vol. 10(1), Vasa, 2001b, pp. 65-104.

12. HILEY, A., A. COLLIS, J.A. WILSON, Through the Wardrobe: a Generic Platform to Foster the Evolution of Creative Problem-solving Skills. International Conference on Creativity or Conformity: Building Cultures of 
Creativity in Higher Education, Cardiff, Wales, UK, 2007.

13. HOOVER-DEMPSEY, K. V., A. C. BATTIATO, J. M. T. WALKER, R. P. REED, J. M. DEJONG, K. P. JONES, Parental Involvement in Homework. Educational Psychologist, Vol. 36(3), 2001, pp. 195-209.

14. HUTCHISON, C. B., Cultural Constructivism: The Confluence of Cognition, Knowledge Creation, Multiculturalism, and Teaching. Intercultural Education, Vol. 17(3), 2006, pp. 301-310.

15. JACKSON, R., J. KARP, E. PATRICK, A. THROWER, 2006, Social Constructivism Vignette. (Retrieved 5. April, 2008) from http://projects.coe.uga.edu/epltt/index.php? title=Social_Constructivism

16. JAY, E. S., D. N. PERKINS, Problem Finding: The Search for Mechanism. In Runco M.A. (Ed.) The creativity research handbook. Hampton Press, New Jersey, 1997, pp. 257-293.

17. JONASSEN, D., Integration of Problem Solving into Instructional Design. In R. Reiser \& J. Dempsey (Eds.) Trends and issues in instructional design and technology, Merrill/Prentice Hall, Upper Saddle River, NJ, 2002.

18. LAREY, T. S., P. B. PAULUS, Group Preference and Convergent Tendencies in Small Groups: A Content Analysis of Group brainstorming performance. Creativity Research Journal, Vol. 12(3), 1999, pp. 175-185.

19. LUCKIN, R., J. AKASS, J. COOK, P. DAY, N. ECCLESFIELD, F. GARNETT, M. GOULD, T. HAMILTON, A. WHITWORTH, Learner-Generated Contexts: Sustainable Learning Pathways Through Open Content. OpenLearn 2007 - Researching Open Content in Education. Open University, Milton Keynes, 2007, pp. 30-31.

20. MCCARTHEY, S. J., Home-school Connections: A Review of the Literature. The Journal of Educational Research, Vol. 99(3), 2000, pp. 145-167.

21. MCMAHON, M., Social Constructivism and the World Wide Web - A Paradigm for Learning. ASCILITE Conference 1997. Perth, Australia.

22. PAULUS, P. B., K. L. DUGOSH, M. T. DZINDOLET, H. COSKUN, V. L. PUTMAN, Social and Cognitive Influences in Group Brainstorming: Predicting Production Gains and Losses. European Review of Social Psychology, Vol. 12(1), 2002, pp. 299-325.

23. RUNCO, M. A., Creativity: Theories and Themes: Research, Development, and Practice. Elsevier Academic Press, Amsterdam, 2007.

24. RUNCO, M. A., G. DOW, Problem Finding. In Runco, M. A. and Pritzker, S.R. (Eds) Encyclopedia of Creativity, Vol. 2. Academic Press, San Diego, 1999, pp. 433-435.

25. SHOTTER, J., Cultural Politics of Everyday Life. Open University Press, Buckingham, 1993.

26. SMITH, G.F., Towards a Logic of Innovation. The International Handbook on Innovation. Elsevier Science Ltd, 2003.

27. The Webster Dictionary, 2005, (Retrieved 7. Des. 2010).http://www.m-w.com/

28. THORSTEINSON, G., Innovation and Practical Use of Knowledge. DATA International Research Conference 2002. The Design and Technology Association (eds) Norman, Spendlove and Grover, 2002, pp. 177-183.

29. THORSTEINSSON, G., H. G. DENTON, Ideation in a Virtual Learning Environment: A Pilot Project from Iceland in Innovation Education. In Norman, E.W.L., Spendlove, D. and OwenJackson, G. (Eds), The Design and Technology Association International Research Conference book 2006. Telford, July 2006, The Design and Technology Association, Wellesbourne, pp. 155-164.

30. THORSTEINSSON, G., Innovation in the Elementary School. Uppeldi Vol. 6(1), 1998, pp. 14-148.

31. THORSTEINSSON, G., T. PAGE, A. NICULESCU, Using Virtual Reality for Developing Design Communication, Studies in Informatics and Control, Vol. 19(1), 2010, ISBN 1220-1766. pp 93-106. 
32. THORSTEINSSON, G., T. PAGE, M. LEHTONEN, A. NICULESCU, Innovative Technology Education in a Virtual Reality Learning Environment, Studies in Informatics and Control, Vol. 16 (3), 2007, ISBN 1220-1766, pp 297-306.

33. VIDAL, R. V. V., FRI\&FRO - et fremtidsvæksted. (in Danish) unpublished, IMM, DTU, Denmark, 2006, p. 22.
34. VYGOTSKY, L.S., Mind in Society: The Development of Higher Psychological Processes. Harvard University Press, Cambridge, 1978.

35. WENGER, E. 2005, Communities of Practice A Brief Introduction. Retrieved (28 Mar 2009) from http://www.ewenger.com/theory/communit ies_of_practice_intro_WRD.doc. 